\title{
O PAPEL DOS GRUPOS DE PRESSÃO: UMA ANÁLISE DE POSSÍVEIS RELAÇÕES DOS CUSTOS ELEITORAIS ELEVADOS E RENDAS PETROLÍFERAS MUNICIPAIS
}

\author{
THE ROLE OF PRESSURE GROUPS: AN ANALYSIS OF POSSIBLE \\ RELATIONS BETWEEN HIGH ELECTION COSTS AND MUNICIPAL OIL \\ REVENUES
}

\author{
Aldo Tostes de Almeida ${ }^{1}$ \\ Rodrigo Machado Vilani ${ }^{2}$
}

\begin{abstract}
RESUMO
Os grandes volumes de recursos provenientes de royalties repassados a municípios produtores de petróleo proporcionam inúmeras possibilidades de investimentos em infraestrutura e equipamento urbano para as administrações públicas. Porém, a qualificação e distributividade de tais investimentos podem ser questionadas, uma vez que seguidos índices de desenvolvimento, como o IDH e o de GINI, apresentam quedas quando comparados a outras localidades não recebedoras dos referidos recursos. Este trabalho objetiva trazer à discussão a existência de grupos de pressão atuando de forma ostensiva, tanto no campo político quanto no econômico, indicando uma tendência de apropriação dos benefícios líquidos advindos de tais investimentos. O município de Campos dos Goytacazes - RJ serviu de cenário para a análise da aplicação dos investimentos públicos, de acordo com o estrato de renda da população beneficiada. Tal fator foi o instrumento de corte populacional que captou uma tendência de direcionamento dos investimentos públicos para áreas de maior poder aquisitivo, na medida em que os repasses de royalties para o município aumentaram.
\end{abstract}

Palavras-chave: Royalties; Gastos públicos; Democracia representativa.

\begin{abstract}
The considerable volumes of resources from royalties passed on to oil-producing districts and towns provide numerous possibilities for investment in urban infrastructure and equipment for public administration. However, the purposes and forms of distribution of these investments can be questioned because, according to development indexes such as the HDI and the Gini Index, there has been a drop in development levels in comparison with other districts and towns that do not receive these royalties. This study aims to discuss the existence of pressure groups that operate ostensibly in both the political and economic field, which may mark a trend of appropriation of the net benefits of these investments. The application of public investments in Campos dos Goytacazes, a town in Rio de Janeiro State, was analyzed according to the income level of the population that benefits from these investments. The study found that the investments tended to be made in areas with higher buying power and this trend grew as the amount of royalties in the town increased.
\end{abstract}

Key words: Royalties; Public expenditure; Representative democracy.

\footnotetext{
1 Mestrando em Planejamento Regional e Gestão de Cidades pela Universidade Candido Mendes (UCAM).

2 Professor do Programa de Pós-Graduação em Planejamento Regional e Gestão de Cidades da Universidade Candido Mendes (UCAM).
} 


\section{Introdução}

Os grupos de pressão são elementos pertencentes a qualquer estrutura política e fazem parte do processo de formação e tomada de decisões dentro da hierarquia normal do poder público. Porém, é preciso que seja estabelecida a dinâmica política para compreender todo o processo. Conforme ressalta Esparcia (2011), quando as ações e objetivos são internos ao grupo, ou seja, visam a um ganho efetivo (ad intra) no processo, a exemplo, em uma eleição para diretorias de associações, caracterizam-se a formação de grupos de interesse. Por outro lado, quando as ações e proposições são exógenas ao grupo, basicamente de cunho político, são formados grupos de pressão, dotados de um grau de interesse parcial e direcionado em contraponto a interesses públicos gerais.

A questão chave para o entendimento dos grupos de pressão é a sua capacidade de articulação de interesses, ou seja, a competência que os indivíduos têm de se aglutinar visando estabelecer influência sobre a tomada de decisão política. Buchanan e Tullock (1962) salientam que a eficácia dos grupos de pressão é dada por diversos fatores, entre os quais se destacam a capacidade de mobilização de seus agentes, os recursos financeiros e humanos disponíveis, a eficiência em conseguir coesão, adequação de seus interesses à sociedade e o acesso aos gestores públicos e/ou parlamentares.

Outro ponto debatido por Esparcia (2011) é que, a partir da formação de grupos de pressão, ocorre uma redução dos canais de demandas públicas, de modo a controlar e a exercer um controle estrutural sobre o processo de decisão e alocação de recursos.

[...] os grupos de pressão, assim como os partidos políticos, como "reguladores estruturais do volume de demandas", pois são os indivíduos que controlam a entrada de pedidos no sistema político. Esse controle se concretiza na redução do volume e da diversidade das solicitações, por meio da combinação de duas ou mais demandas em uma única demanda. $\mathrm{O}$ processo de redução permite canalizar o fluxo de exigências, ordenando-as e reduzindo-as a um número limitado de alternativas, que são apresentadas aos gestores públicos. Pode-se, assim, tratar de reunir requerimentos semelhantes que foram apresentados de maneira dispersa. Entretanto, a redução não consiste unicamente na reunião e organização de exigências gerais, já que também reúne exigências específicas em uma demanda global. (ESPARCIA, 2011, p. 70).

Em síntese, caracteriza-se a formatação de um grupo de pressão à medida que ações são desempenhadas para selecionar as demandas públicas e o sucesso do direcionamento da alocação de recursos do sistema. Os mecanismos que revertem as necessidades da população em exigências, segundo Buchanan e Tullock (1962), são a regulação estrutural e a regulação cultural, sendo que, por meio dessas aplicações endógenas e exógenas, se dá a dinâmica de ação de um grupo de pressão em um ambiente político. Outro ponto que oferece subsídio ao entendimento desse processo que tenciona decisões é a representação empresarial de interesses específicos, principalmente quando acontecem por meio de canais diretos entre os grupos e as autoridades públicas. 
A identificação de grupos de pressão atuando nas cidades que possuem rendas petrolíferas não é latente, uma vez que existe uma tendência natural de se demandarem nesses municípios, por parte do poder público, um volume maior de bens e serviços do que em cidades onde a receita não é complementada com royalties. Esse processo acaba por criar um mecanismo de retroalimentação, em que o maior dano da concentração do poderio econômico é a crescente capacidade de influenciar as decisões públicas por meio de dinheiro.

Estudando especificamente o universo das cidades produtoras de petróleo do norte do Estado do Rio de Janeiro (ERJ), Terra, Oliveira e Givisiez (2013) elaboram uma análise qualiquantitativa acerca da aplicação socioespacial dos recursos orçamentários da cidade de Campos dos Goytacazes (CGO) referente às gestões executivas municipais no período de 1993 a 2004. A metodologia usada incorporou elementos estatísticos para quantificar a alocação de investimentos públicos de acordo com o estrato de renda populacional em cada Região Municipal (RM), classificando as regiões socioespacialmente por meio de um modelo de análise multifatorial, condensando seu status socioeconômico (renda, educação presença de empregados domésticos, infraestrutura dos domicílios, domicílios improvisados) e seu status familiar (idade média das pessoas residentes, idade média dos chefes de domicílios, densidade domiciliar, e mulheres chefes de domicílio) em quatro estratos populacionais: Baixo Status, Médio Status, Médio Alto Status e Alto Status.

O movimento descrito no Gráfico 1 denota uma elevação nos investimentos públicos por parte da prefeitura de CGO, a partir da segunda gestão, mais precisamente em meados da década de 1990, acentuando-se na terceira gestão, de 2000 a 2004. Resultado esse em grande parte oriundo das receitas de royalties petrolíferos advindas do novo marco regulatório promulgado pela Lei $\mathrm{n}^{\circ}$ 9.478/1997.

Entretanto, o ponto comum é que, no decorrer da terceira gestão (2000-2004), percebeu-se uma acentuação na concentração dos investimentos em infraestrutura nas áreas de maior poder aquisitivo, revertendo uma proporção anterior de dedicação maior dos recursos às áreas de menor status social.

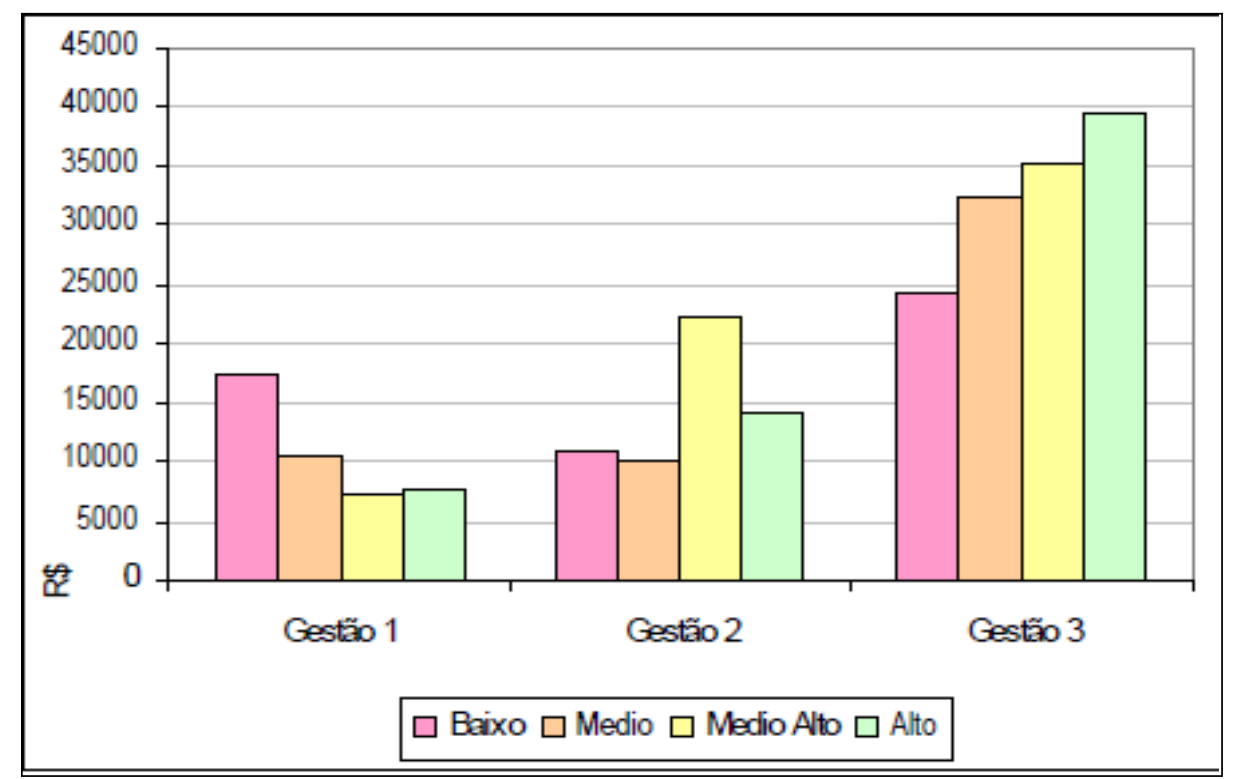

GRÁFICO 1 - Evolução dos investimentos per capita por gestão municipal, Campos dos Goytacazes (1993-2004) 
Fonte: Terra, Oliveira e Givisiez (2013, p. 10).

Conforme ressaltam Terra, Oliveira e Givisiez (2013, p. 12), em Campos dos Goytacazes, município com a maior arrecadação de royalties no país, não foi identificada uma relação entre essa vantagem orçamentária e o aumento de justiça social e outros benefícios líquidos diretos para as camadas menos favorecidas da população. Os autores afirmam, ainda, que "os resultados da investigação empírica realizada sugerem que a folga orçamentária não se constitui em um fator determinante da eficiência na alocação dos recursos públicos municipais em favor dos segmentos populacionais menos favorecidos."

A principal conclusão obtida pelos autores supracitados em relação a CGO é a existência da ocorrência de um benefício socioespacial na destinação de recursos, pois nas primeiras gestões analisadas, 1993-2000, mesmo com um volume menor de investimentos disponíveis, eles foram utilizados de forma mais eficiente e igualitária, exibindo uma dispersão em várias áreas do município e de estratos de renda variada. A partir da gestão governamental 2000-2004, volumes crescentes de recursos de royalties foram utilizados em uma proporção muito maior em regiões das cidades consideradas de renda já elevadas e possuidoras de recursos básicos de saneamento e infraestrutura já existentes.

Diante de tal cenário, é válida a abordagem de Vetter e Massena (1982), na qual discutem a tendência dos grupos de maior poder aquisitivo de pressionar o governo para que obras de infraestrutura sejam contempladas em seus bairros, colhendo principalmente o benefício líquido da valorização dos imóveis e seus entornos. Face ao exposto, a pergunta que emerge de tais questionamentos é referente à explicação e qualificação das ligações dos grupos de pressão que operam na apropriação de benefícios líquidos com os grandes orçamentos das cidades produtoras de petróleo e recebedoras de royalties, ou seja, o quanto é influenciada a aplicação dos recursos dos royalties pelos grupos de pressão existentes.

Como forma de aplicar a reflexão teórica apresentada à realidade dos municípios brasileiros, propõe-se um recorte nos municípios com altos repasses de royalties, a partir dos dados referentes aos custos eleitorais das chapas vencedoras apresentados ao Tribunal Superior Eleitoral (TSE). Assim, o próximo item procura apontar as características do mecanismo de retroalimentação entre poder público e poder econômico e suas consequências sobre o processo de elaboração de políticas públicas.

\section{Doações eleitorais como ferramenta de pressão econômica}

Uma análise mais focada de como os grupos econômicos têm influenciado os resultados políticos, em especial as campanhas eleitorais, permite uma compreensão de como o agrupamento de interesses tem resultado em grupos de pressão extremamente fortes. A primeira abordagem que deve ser feita é no tocante ao volume de recursos empregados nos municípios que possuem rendas petrolíferas quando comparados a outros municípios com a mesma população em outras regiões do estado e do país. Em segundo plano, a qualificação da origem das doações de campanha mostra que os recursos oriundos de pessoas jurídicas são superiores aos recursos providos por pessoas físicas.

A hipótese é a de que, em municípios recebedores de royalties, o custo das campanhas políticas é muito maior, reforçada pelo fato de que, em tais localidades, a formação de grupos de pressão permite maior aglutinação de poder em torno de representantes comprometidos em grande parte com os objetivos do próprio grupo político. Buscando-se comprovação de tal 
abordagem, foram selecionados registros das doações de campanha contidas na prestação de contas ao TSE dos candidatos que venceram as eleições para prefeito no ano de 2012 (TSE, 2012). Adicionalmente, os municípios foram organizados por faixa populacional, utilizandose dados do Censo 2010 do Instituto Brasileiro de Geografia e Estatística (IBGE, 2010), estratificando-os em três níveis: municípios com população média de 450 mil habitantes, municípios com população média de 230 mil habitantes e municípios com população média de 20 mil habitantes (Tabela 1).

TABELA 1 - Cortes populacionais das cidades

\begin{tabular}{l|c|l|l|l|c}
\hline \multicolumn{5}{c}{ Faixa de habitantes } & \multicolumn{2}{c}{ 20 mil } \\
\hline 450 mil & Hubitantes & Município & Habitantes & Município & Habitantes \\
\hline $\begin{array}{l}\text { Mampos-RJ } \\
\text { Belford Roxo- } \\
\text { RJ }\end{array}$ & 472.300 & Macaé-RJ & 217.951 & $\begin{array}{l}\text { Quissamã- } \\
\text { RJ }\end{array}$ & 20.242 \\
\hline $\begin{array}{l}\text { Porto Velho- } \\
\text { RO }\end{array}$ & 444.596 & Magé-RJ & 230.568 & $\begin{array}{l}\text { Miracema- } \\
\text { RJ }\end{array}$ & 26.843 \\
\hline
\end{tabular}

Fonte: IBGE (2010).

Após o corte populacional, foi escolhido, pelo critério de receita de royalties, o município produtor de maior receita, seguido por outro que recebe participação indireta e outro município de outro estado sem nenhuma receita de royalties. Esquematicamente, os dados podem ser apresentados como segue (Tabela 2):

TABELA 2 - Municípios com população média de 450 mil habitantes

\begin{tabular}{lrrrr}
\hline Município & $\begin{array}{l}\text { Custo da } \\
\text { campanha } \\
\text { vencedora }\end{array}$ & Habitantes $\begin{array}{l}\text { Receita de royalties } \\
\text { ano 2012 }\end{array}$ & $\begin{array}{l}\text { Custo per } \\
\text { capita das } \\
\text { campanhas }\end{array}$ \\
\hline Campos - RJ & $\mathrm{R} \$ 2.268 .378,49$ & 472.300 & $1.165 .510 .585,53$ & $\mathrm{R} \$ 4,80$ \\
Belford Roxo-RJ & $\mathrm{R} \$ 572.848,67$ & 474.596 & $\mathrm{R} \$ 10.596 .573,09$ & $\mathrm{R} \$ 1,21$ \\
Porto Velho-RO & $\mathrm{R} \$ 947.303,50$ & 442.701 & $\mathrm{R} \$ 0,00$ & $\mathrm{R} \$ 2,14$ \\
\hline
\end{tabular}

Fonte: TSE (2012) e Inforoyalties (2012).

Os dados demonstram que os gastos relativos à campanha vencedora em Campos dos Goytacazes são, nominalmente, superiores aos de Belford Roxo em 395\%, representando um alto custo por habitante. Quando as doações são qualificadas sobre a fonte, verifica-se que a campanha vencedora recebeu $99 \%$ de suas doações de pessoas jurídicas (Gráfico 2), caracterizando um predomínio de interesses privados no financiamento do processo de escolha do representante público. 


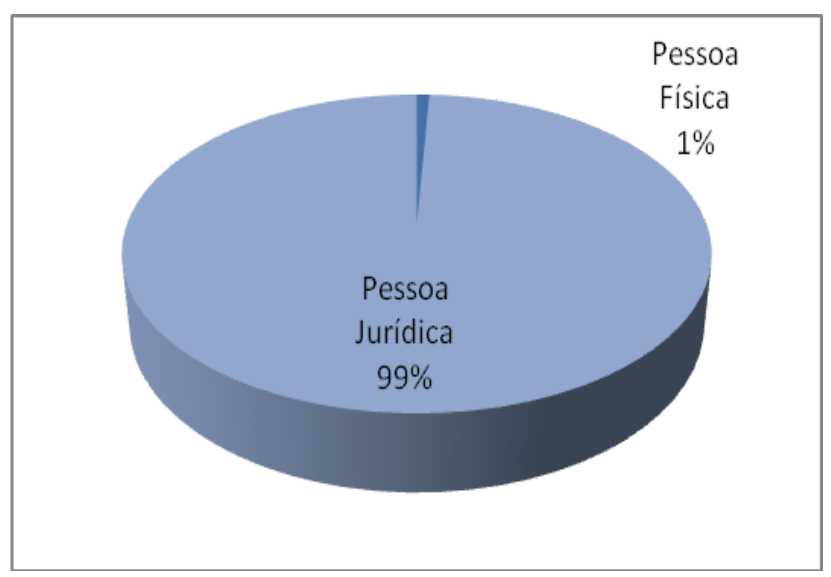

GRÁFICO 2 - Qualificação da natureza jurídica das doações para a campanha vencedora em Campos do Goytacazes na eleição para prefeito de 2012

Fonte: TSE (2012).

Na literatura política, autores como Zovatto (2005) e Graziano (1997) versam sobre a temática de financiamento de campanhas eleitorais, tendo como consenso a ideia de que os detentores do poder econômico, estejam em grupos de pressão ou individualmente, tendem a atuar fortemente no financiamento das campanhas eleitorais. Seu principal objetivo é aumentar a própria influência nos mais diversos cenários, uma vez que o campo político é um terreno fértil para tal influência. Conforme Zovatto (2005), no ambiente pós-eleitoral esse domínio pode assumir diversas formas, desde o direcionamento de licitações, concessão de subsídios, decisões legislativas e sobretudo políticas públicas que beneficiem grupos em particular.

Analisando a Tabela 3, verifica-se que o custo per capita das campanhas aumenta à medida que a população diminui, sendo que o corte populacional é da faixa de 230 mil habitantes. Essa análise se aplica mais intensamente no município de Macaé, que possui alta receita com royalties.

TABELA 3 - Municípios com população média de 230 mil habitantes

\begin{tabular}{l|r|r|r|r}
\hline Município & $\begin{array}{l}\text { Custo da } \\
\text { campanha } \\
\text { vencedora }\end{array}$ & Habitantes & $\begin{array}{l}\text { Receita de royalties } \\
- \\
\text { ano 2012 }\end{array}$ & $\begin{array}{l}\text { lusto per } \\
\text { capita } \\
\text { das } \\
\text { campanhas }\end{array}$ \\
\hline Macaé-RJ & $\mathrm{R} \$ 1.660 .105,01$ & 217.951 & $\mathrm{R} \$ 524.269 .854,78$ & $\mathrm{R} \$ 7,62$ \\
\hline Magé-RJ & $\mathrm{R} \$ 783.024,50$ & 230.568 & $\mathrm{R} \$ 54.547 .903,77$ & $\mathrm{R} \$ 3,40$ \\
\hline $\begin{array}{l}\text { Divinópolis- } \\
\text { MG }\end{array}$ & $\mathrm{R} \$ 730.339,00$ & 217.404 & $\mathrm{R} \$ 0,00$ & $\mathrm{R} \$ 3,36$ \\
\hline
\end{tabular}

Fonte: TSE (2012) e Inforoyalties (2012).

A Tabela 4 tem sua análise focada em municípios com população média de 25 mil habitantes, cujo dado principal é o descolamento do valor per capita do custo eleitoral em 
Quissamã-RJ, sendo que cidades de população similar apresentam custo $747 \%$ menor por habitante.

TABELA 4 - Municípios com população média de 25 mil habitantes

\begin{tabular}{l|l|r|l|l}
\hline Município & $\begin{array}{l}\text { Custo da } \\
\text { campanha } \\
\text { vencedora }\end{array}$ & Habitantes & \begin{tabular}{l} 
Receita de royalties \\
\multicolumn{1}{l|}{ ano 2012 }
\end{tabular} & $\begin{array}{l}\text { Custo per } \\
\text { capita } \\
\text { das } \\
\text { campanhas }\end{array}$ \\
\hline $\begin{array}{l}\text { Quissamã- } \\
\text { RJ }\end{array}$ & $\mathrm{R} \$ 487.965,50$ & 20.242 & $\mathrm{R} \$ 91.638 .268,81$ & $\mathrm{R} \$ 24,11$ \\
\hline $\begin{array}{l}\text { Miracema- } \\
\text { RJ }\end{array}$ & $\mathrm{R} \$ 152.867,09$ & 26.843 & $\mathrm{R} \$ 7.152 .688,67$ & $\mathrm{R} \$ 5,69$ \\
\hline Astorga-PR & $\mathrm{R} \$ 83.362,36$ & 24.698 & $\mathrm{R} \$ 0,00$ & $\mathrm{R} \$ 3,38$ \\
\hline
\end{tabular}

Fonte: TSE (2012) e Inforoyalties (2012).

Quando se examinam os dados comparados per capita, acura-se que existe uma correlação direta entre a receita de royalties recebidos pelos municípios e os custos da campanha vencedora da eleição. Segundo Brunell (2005), a existência de acirramentos políticos e elevações abruptas de dinheiro em campanhas advêm, em grande parte, do fato de que os grupos de pressão desejam prioritariamente estabelecer vínculos de poder e não ter restrições de acesso aos governantes.

A existência de grandes repasses de recursos não vinculados, como royalties, cria um ambiente propício para que grupos de pressão se estruturem de modo a garantir o acesso irrestrito ao poder local, além de dificultar o processo de oposição. O escopo do trabalho realizado por Brunell (2005):

está além de explicar todas as variáveis diferentes que talvez afetem como um grupo escolhe um candidato, não pretende-se fazer generalizações amplas sobre estes tipos de escolhas, porém, os grupos de interesse querem evitar serem bloqueados do processo de politico completamente. Dar dinheiro para moderar membros encarregados do partido de oposição permite uma entrada para estes grupos nos partidos de oposição. (BRUNELL, 2005, p. 683). 


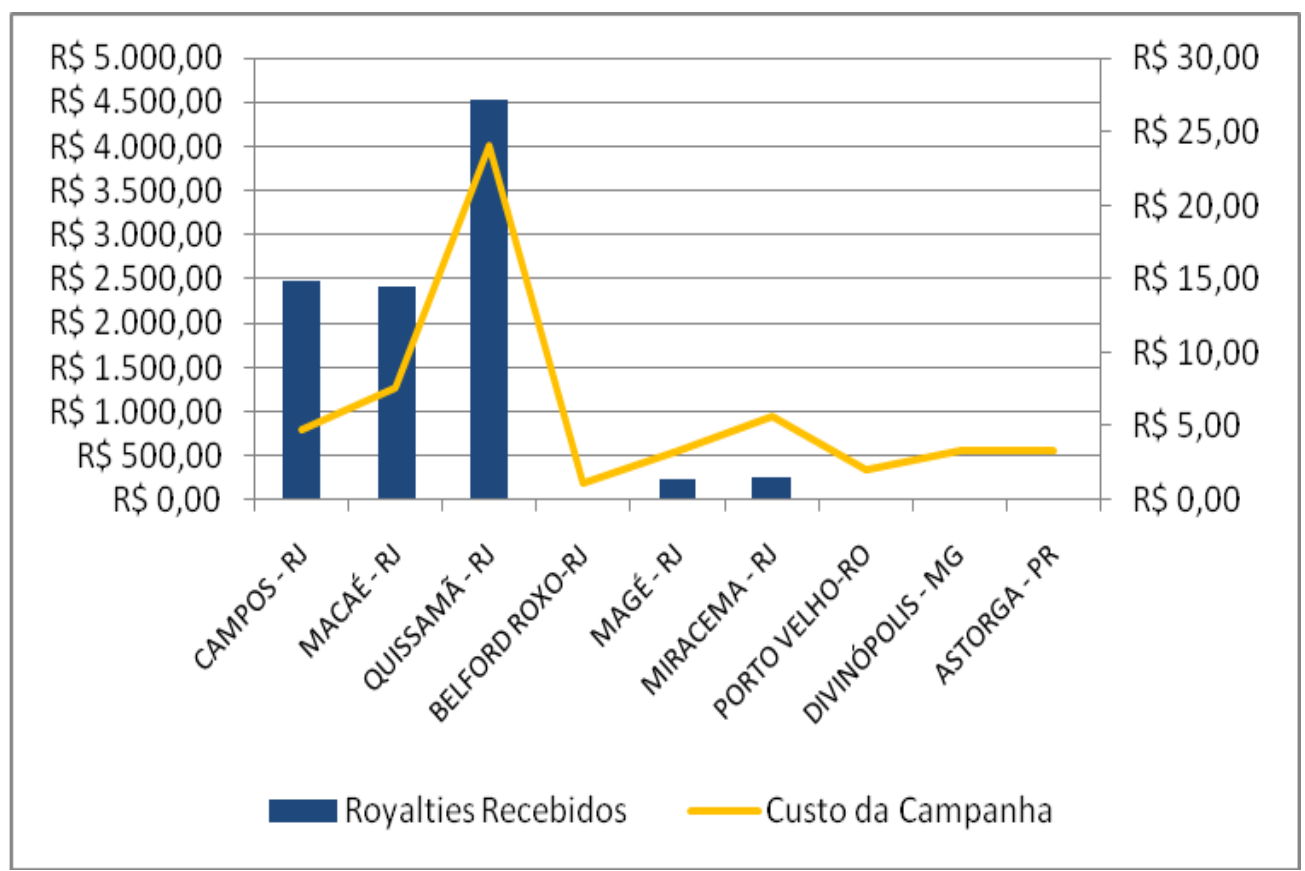

GRÁFICO 3 - Receita de royalties de petróleo e custo da campanha na eleição para prefeito de 2012, em dados per capita

Fonte: TSE (2012) e Inforoyalties (2012).

A argumentação de Brunell (2005) pode ser reforçada por meio de um exame da natureza jurídica das doações de campanhas, apresentada no Gráfico 4, de modo a comparar tais dados em municipalidades de população aproximada, mas com perfis arrecadatórios diferenciados.

O município de Astorga, no estado do Paraná, tem aspecto populacional similar ao de Quissamã/RJ, porém exibe perfil diferenciado no que tange ao financiamento de suas campanhas. No município paranaense, $42 \%$ das doações foram efetuadas por pessoas físicas, enquanto que o município de Quissamã apresenta $74 \%$ de seus custos de campanha financiados por doações de pessoas jurídicas.

Tais elementos indicam a existência de maior pressão econômica operando no município fluminense, uma vez que Zovatto (2005) reforça a concepção de que grupos financeiros se associam para reforçar o poder econômico e consequente influência política.

Comparativamente, a interessante correlação apontada no Gráfico 3 indica uma tendência de aglutinação de capital em torno de campanhas políticas que disputam prefeituras com orçamentos inflados pela arrecadação de royalties. 


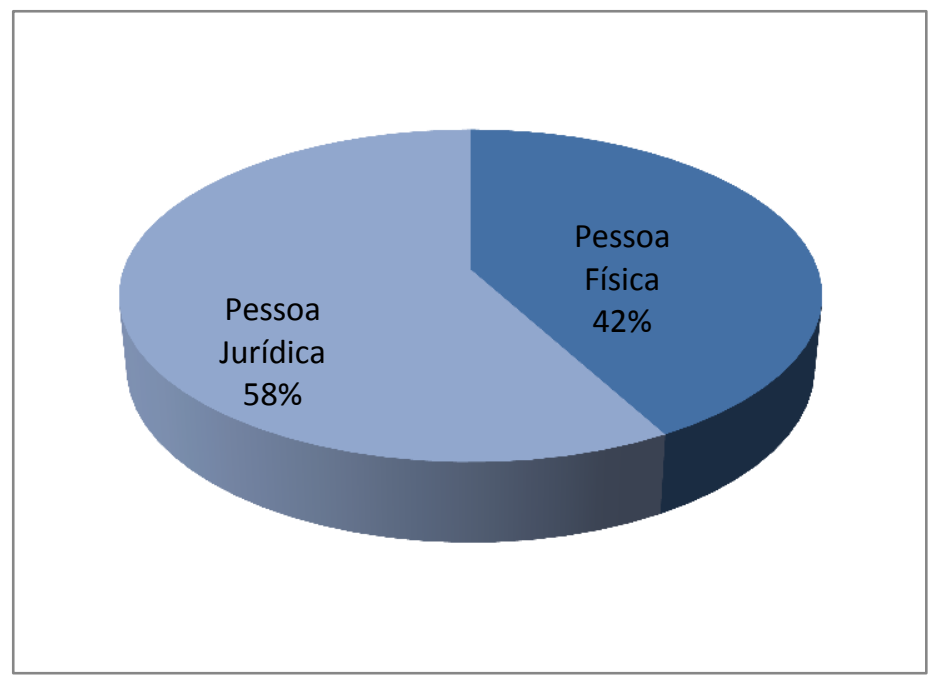

GRÁFICO 4 - Qualificação da natureza jurídica das doações para campanha vencedora em Astorga-PR na eleição para prefeito de 2012

Fonte: TSE (2012).

O escopo do presente trabalho não permite um exame aprofundado do desenvolvimento municipal em cidades recebedoras de royalties. Porém, permite que, $a$ posteriori, se possa corroborar a hipótese de que as demandas da população em grande parte não são atendidas ou, na melhor das situações, não priorizadas, uma vez que existe um comprometimento tácito do poder público com interesses privados que em grande monta financiaram o processo eleitoral.

A ocorrência de situações de direcionamento de políticas públicas abre campo para o debate de que mecanismos eventualmente poderiam ser criados para conseguir maior controle da ação de grupos de interesse e de pressão sobre o poder público municipal. Complementando esta análise, Brunell (2005) entende que os grupos de interesse procuram maximizar sua influência política, enquanto partidos políticos estão focados em maximizar o número de acentos no congresso.

Do ponto de vista da práxis política, a problemática do processo de interferência de grupos de pressão nas decisões dos gestores públicos se resume a uma esfera puramente político-partidária, e em até alguns pontos fisiológica, no sentido de ganhos e benefícios diretos tratados no âmbito econômico principalmente. Entretanto, os efeitos danosos do direcionamento das políticas públicas pelos grupos de interesse podem ser localizados por meio de dados referentes à ineficiência e piora de índices de desenvolvimento urbano e social.

O artigo de Postali (2008) ressalta que, empiricamente, uma análise de resultados do Índice de Desenvolvimento Humano (IDH) e do Índice de Gini para municípios recebedores de royalties, confrontados com a média brasileira, mostra que, mesmo utilizando-se uma margem orçamentária para investimentos muito maior, esses municípios não conseguem tangibilizar tal melhoria para a população. Ou seja, Postali (2008) confirma a analogia de que os municípios que tiveram suas receitas com royalties aumentadas mostraram crescimento negativo no que tange à melhoria dos índices de desenvolvimento humano e socioeconômico. Na perspectiva teórica de autores como Postali (2008), bem como de Terra, Oliveira, Givisiez (2013), sendo CGO o município brasileiro que mais recebe royalties, seu exemplo pode ser utilizado para reforçar o entendimento de que, mesmo elevando-se em termos de volume, os 
investimentos não foram aplicados de forma a proporcionar ganho equânime de desenvolvimento social no período de 1993-2004.

O entendimento de que existe uma correlação direta entre elevação de gastos eleitorais com o aumento do interesse no poder político por grupos de pressão econômica proporciona o subsídio teórico necessário para a formulação de possíveis alternativas que mitiguem esses efeitos no trato do orçamento público dos municípios produtores e recebedores de royalties em especial. Gohn (2001, p. 7) ressalta que os "canais de participação que articulam representantes da população e membros do poder público estatal em práticas que dizem respeito à gestão de bens públicos resultam em uma melhor eficiência de gestão". O bem público, neste caso, tende a ganhar em termos de práticas de gestão na medida em que vários grupos de interesse se arranjam de modo a conciliar os objetivos e buscar um consenso coletivo.

Dessa forma, pode-se visualizar a formulação de conselhos locais gestores de políticas públicas como ferramenta de promoção dos conceitos de controle e governança. Em caso especial, enfatiza-se a possibilidade de o controle ser uma ferramenta endógena à máquina pública, de modo a ocorrer organicamente sem imposição externa. O modelo de controle sobre os governantes deveria, segundo Arretche (1996), seguir uma introjeção de valores que viabilizassem uma responsabilização solidária do tipo "self-enforced" pelo agente público.

O que se planeia nessa lógica é a estruturação de mecanismos que, com o passar do tempo, façam com que os conceitos de governança, transparência e accountability estejam arraigados na gestão pública de forma ampla, mitigando-se os efeitos nefastos dos grupos de pressão, tanto eleitoralmente quanto na influência posterior da alocação dos recursos públicos.

\section{Considerações finais}

Primeiramente, foi apresentada a principal diferença entre grupos de pressão e interesse, que reside no fato de os grupos de pressão apresentarem características de objetivos puramente privados, enquanto que os grupos de interesse mostram formatação mais difusa no que tange a seus objetivos. Entretanto, essa análise perpassa pelo exame de que são organizações de tipo associativo, cujos membros têm um interesse comum, advindo em grande parte de fatores sociais, econômicos, normas sociais e crenças em comum, além do fato de que, em tais organizações, conforme observado por Pereira (2000), existe uma diferenciação latente entre os agentes dos grupos de interesse.

No presente trabalho foram analisadas as possíveis características desses grupos nos municípios do norte fluminense, em especial em CGO, que figura como maior recebedor de royalties. Observou-se que, apesar da maior arrecadação, houve maior concentração de investimentos em infraestrutura em regiões como a de CGO, detentora de maior nível de renda, em detrimento das áreas de menor poder aquisitivo.

Terra, Oliveira e Givisiez (2013, p. 12) ressaltam que o principal instrumento de análise quantitativa que evidencia um perfil de acirramento do embate eleitoral entre grupos de poder político pode ser captado por meio de um exame das contas eleitorais referente às campanhas vencedoras nos municípios, entre os recebedores de royalties, recebedores indiretos, e os não recebedores, de mesma população, nas eleições municipais de 2012. Segundo dados apurados pelo TSE (2012), e compilados neste trabalho, os custos per capita das campanhas chegam a ser $747 \%$ maiores em municípios que recebem royalties, 
comparados a municípios de mesma população que não têm o mesmo volume de recursos disponíveis em seus orçamentos.

Pode-se assim admitir que, nesses municípios, uma tendência de fortalecimento dos grupos de interesses, por um lado, e o enfraquecimento da gestão democrática e participativa no uso dos royalties, resultando no descompasso apresentado entre arrecadação e melhoria da qualidade de vida da população.

Diante desse cenário, a adoção de conselhos de gestão para os royalties do petróleo é um importante avanço no que tange à melhoria da alocação desses recursos. No entanto, para que se instrumentalize uma instituição com capacidade de articulação e que consiga efetiva mudança para a realidade municipal, deve-se focar na elaboração de uma legislação que tenha a missão do conselho fiscalizador de forma definida e coesa.

Com base nas reflexões feitas anteriormente, emerge a necessidade de que se faça uma junção das motivações existentes na sociedade para melhor utilização dos recursos dos royalties, com a necessidade de maior participação social na decisão de uma renda tão importante quanto àquela relativa à exploração petrolífera. Não obstante, uma maior transparência nos gastos públicos dos municípios, bem como a adoção de ferramentas para maximizar o accountability dessa renda, cuja tendência é a de otimizar sua alocação.

Por fim, espera-se que a atuação da sociedade civil organizada, congregada com a articulação entre as escalas de governo, permita a criação de um arcabouço institucional que delimite a ação coletiva dos grupos de interesse no que tange ao direcionamento das rendas petrolíferas, além de favorecer a adoção de princípios de eficiência, eficácia e accountability.

\section{REFERÊNCIAS}

ARRETCHE, Marta Teresa da Silva. O mito da descentralização: maior democratização e eficiência. Revista Brasileira de Ciências Sociais, São Paulo, v. 11, n. 31, p. 50-77, 1996.

BRUNELL, Thomas L. The relationship between political parties and interest groups: explaining patterns of PAC contributions to candidates for congress. Political Research Quarterly, v. 58, n. 4, p. 681-688, Dec. 2005.

BUCHANAN, James M.; TULLOCK, Gordon. The calculus of consent: logical foundations of constitutional democracy. Ann Arbor, MI: University of Michigan Press, 1962.

ESPARCIA, Antonio Castillo. Nuevos escenarios de participación política: análisis de las estrategias de comunicación de los grupos de presión (lobbies). Organicon, Barcellona, v. 14, n. 8, p. 64-86, 2011.

GOHN, Maria da Glória. Conselhos Gestores e Participação Sociopolítica. São Paulo: Cortez, 2001.

GRAZIANO, Luigi. O lobby e o interesse público. Revista Brasileira de Ciências Sociais, São Paulo, v. 12, n. 35, fev. 1997. 
IBGE - INSTITUTO BRASILEIRO DE GEOGRAFIA E ESTATÍSTICA. Censo Demográfico 2010. Disponível em: <http://censo2010.ibge.gov.br>. Acesso em: 28 jul. 2013.

INFOROYALTIES - BOLETIM DE DADOS DE ROYALTIES (Campos dos Goytacazes). Universidade Candido Mendes. Receita Municipal de Royalties ano de 2012. Banco de dados de royalties, Mestrado em Planejamento Regional e Gestão de Cidades da UCAMCampos dos Goytacazes-RJ. Disponível em: <http://inforoyalties.ucam-campos.br/>. Acesso em: 13 dez. 2012.

PEREIRA, Paulo Trigo. Governabilidade, grupos de pressão e o papel do Estado. A Reforma do Estado em Portugal (problemas e perspectivas), Lisboa: Bizâncio, 2000.

POSTALI, Fernando Antonio Slaibe. Resource curse, petroleum royalties and Municipal growth in Brazil. In: CONGRESS OF THE EUROPEAN REGIONAL SCIENCE ASSOCIATION, 48., 2008, Liverpool. Proceedings... European Regional Science Association (ERSA), 2008. Disponível em: <http://www.royaltiesdopetroleo.ucamcampos.br/index.php?cod=4>. Acesso em: 28 jul. 2013.

TERRA, Denise; OLIVEIRA, Elzira Lúcia de; GIVISIEZ; Gustavo Henrique Naves. Os municípios "novos ricos" do petróleo são mais solidários com sua população? Disponível em: <http://www.royaltiesdopetroleo.ucam-campos.br/?cod=4>. Acesso em: 28 jul. 2013.

TSE - TRIBUNAL SUPERIOR ELEITORAL. Estatísticas e Resultados da Eleição, 2012. Disponível em: <http://www.tse.jus.br/eleicoes/estatisticas/estatisticas-eleicoes-2012>. Acesso em: 27 jul. 2013.

VETTER, David Michael; MASSENA, Rosa Maria Ramalho. Quem se apropria dos benefícios líquidos dos investimentos do Estado em infraestrutura urbana? Uma teoria de causação circular. In: SILVA, L. A. MACHADO da (Org.). Solo urbano: tópicos sobre o uso da terra. Rio de Janeiro: Zahar, 1982. p. 49-78.

ZOVATTO, Daniel. Financiamento dos partidos e campanhas eleitorais na América Latina: uma análise comparada. Opinião Pública, Campinas, v. 11, n. 2, p. 287-336, out. 2005. 